\title{
The Horizons of Science
}

\section{Ernan McMullin}

There has been an interesting and significant shift over the years in mens' views on the potential science has for indefinite further development. In the heyday of Newtonian science, it seemed as though the basic groundplan of the universe had already been discovered; more would be added doubtless, but the essentials-the laws governing the motions of the smallest particles-were definitively known (it was supposed) and the future could only appear as postscript. With the eclipse of Newtonian certitudes at the beginning of this century, a quite different view arose, one which proposed an unlimited future for science. Two factors contributed especially to this change. One was the growth of atomic physics, culminating in quantum theory, which suggested that physics could progress indefinitely by finding ever finer structures within structures to account for the endlessly diverse properties of things. The other was the replacement of Newtonian mechanics by relativistic mechanics, which destroyed the myth of a basic "core" science, immutable once formulated. added to only by accretion. In the new perspective, it was clear that no theory, especially not the most basic one, mechanics, could ever become immune to fundamental revision. Indeed, one ought to expect that the future of physics would lie in an endless conceptual reconstruction, in which the entire structure would periodically be reshaped.

Over the last fifty years, then, it has gradually come to be assumed that the horizons of science are essentially unlimited, that it can continue to develop for a hundred, a thousand, ten thousand, years in a continuous 
and progressive fashion, never arriving at an irrevisable "complete" theory in any domain, yet never on the other hand facing fundamental barriers to further progress. Thus while the Newtonian-Kantian ideal of a synthetic a priori "pure" physics was given up, it was still assumed that one could (and would) continuously approach the science which would totally disclose the structures of the real. No longer did these structures yield themselves to the easy and definitive insight that both Greek and "classical" (pre-1900) modern science had hoped for. But there did not seem at first sight to be any reason why, given enough time, as near an approximation as one wished to such a definitive insight might not be attainable.

This hope has not been ruled out. But in recent decades, some troublesome doubts have arisen, some yet-distant clouds have come in view on the horizon. In this essay, the most important of these will be briefly discussed. It is important to grasp in what sense the possible barriers to the optimistic program of an indefinitely developing science are proposed here as "barriers". It is not the case that any of them, or all of them together, suggest that science is approaching a definite limit. Rather, what are listed here are signals that warn us against the too-easy optimism of yesteryear. The future development of science could be limited, they would suggest, although it is too early yet to say where the limits (if they $d o$ appear) will be. The conclusion of our inquiry, let it be noted from the start, is not that the future of science can be shown to be limited in specifiable ways, but rather that it is unwarranted to assume (as has too easily been assumed, both in classical and in recent science, though from different standpoints) that it cannot be limited, i.e. that the entirety of the real is, in principle, transparent to systematic scientific inquiry. ${ }^{1)}$

\section{The Gödel Theorem}

Before we get to natural science, let us glance at one stunning "set- 
back" in mathematics, the well-known Gödel theorem (1931):

To those who were able to read Gödel's paper with understanding, its conclusions came as an astounding and melancholy revelation. For the central theorems which it demonstrated challenged deeplyrooted preconceptions concerning mathematical method, and put an end to one great hope that motivated decades of research on the foundations of mathematics. Gödel showed that the axiomatic method... possesses certain inherent limitations when it is applied to sufficiently complex system... even to the familiar arithmetic of cardinal numbers. He also proved, in effect, that it is impossible to demonstrate the internal consistency (non-contradictoriness) of such systems, except by employing principles of inference which are at least as powerful (and whose own internal consistency is therefore as much open to question) as are the logical principles. . . within the systems themselves. ${ }^{2)}$

Ever since Euclid's day, the axiomatic method has been held up as the model for all proof. Attempts have been made to axiomatize physical theories like Newtonian mechanics. The main advantage of such an axiomatization would be to make it easier to prove the consistency of the theory-or so it was thought. But now Godel has shown, by means of a cogent and apparently definitive formal proof, that the consistency of any formal system as complex as, or more complex than, arithmetic cannot be proved. Even more unexpected was the discovery that the completeness of such a system cannot be proved either, which means that no matter how we axiomatize a formal system, there will always be "true" statements in the domain of that system which cannot be derived from the axiom-set chosen.

1) This essay is an abbreviated and revised form of a longer article: "Limits of scientific enquiry" published in Science and the Modern World, ed. J. C. Steinhardt, Plenum Press, New York, 1966. Since then Richard Schlegel has touched on many of these same issues from a rather different point of view in his thoughtprovoking book, Completeness in Science, New York: Appleton-Century-Crofts, 1966.

2) Ernest Nagel and James R. Newman, "Gödel's proof", in The World of Mathematics, ed. J. R. Newman, New York: Simon and Schuster, 1956, vol. 3, p. 1669. 
There is thus a radical barrier to complete axiomatization; the equating of mathematical truth with deducibility from a specifiable axiom-set is no longer possible.

Here, then, is a unique limitation, and in that domain-mathematicswhere limitations might least be expected. For in mathematics we might seem to be dealing with a wholly exhaustible construction, something that could be fully explored and specified by us since it is our construction. Gödel shows that this is not so; the domain of mathematical truth is just as inexhaustible as the domain of physical truth seems to be. It is not the domain that is limited, then, but our means of organizing it deductively, or more basically, our ability to prove that constructions we make are consistent. During the past century, inconsistencies have been detected in various parts of logical and mathematical practice. It is essential to eliminate these, yet it now appears that it is not possible ever to be sure we have done that successfully.

Such a conclusion was utterly unforeseen. The whole progress of mathematics in the past century or so could be interpreted as a sort of liberation from preset limits. Instead of a unique single geometry whose axioms were true in some absolute sense, alternative non-Euclidean geometries gradually came to seem acceptable as "mathematics." No one asked any more about the truth of the axioms of a proposed system: since mathematics was now understood to be a free creation of the human mind, one could only require that it be consistent. This "formalist" approach, fully stated by Hilbert, forced mathematicians to rely only upon relations explicitly given in the axioms and rules of their system. Though these axioms might make use of words like "line" derived from ordinary usage, no recourse could be had to the surplus meaning of such terms. Intuitions based on extrasystemic knowledge could no longer be relied upon. In the 
The Horizons of Science

past they had guided discovery, but now Hilbert argued that such intuitions, because of their physical origin, only restricted the mind, and tended to make it overcautious when new and paradoxical generalizations (like negative numbers or non-Euclidean gemoetries) are proposed.

In Hilbert's new vision of mathematics, the only touchstone of the mathematician's work would be its consistency; there would be no external criterion of any sort. In classical mathematics, on the other hand, the consistency of what was done was implicitly guaranteed by the original extrasystematic reference of such concepts as line or number. There was physical model for Euclidean geometry, the world of experience, and it could not but be consistent. But now that such criteria are discarded, and the intuition is set free, as it were, the danger of antinomy is far greater. For the "new" mathematics, "Gödel's theorem spelt nothing less than a disaster. The single criterion retained by the "new" mathematician is shown to be forever incapable of decisive application in any system of interest. This does not mean that mathematical research is blocked, or even made more difficult. Rather it shows that in this conception of "mathematics," certain highly desirable goals are permanently out of reach.

\section{Intrinsic Limits in Physics}

As physical knowledge becomes more exact, a variety of limits begins to emerge. There is the velocity of light, now thought to be an upper bound on any physical motion. The Speical Theory of Relativity strongly suggests that no form of energy can be transmitted faster than light, and that light itself has a maximum velocity. If this is so, many consequences follow. The most recently discovered far-off galaxies are moving away from us with speeds that get nearer to that of light the further away they are. Are there reaches of the universe that our thought can never compass? We have 
always known that we cannot reach out to the past, though it reaches out to us. It now seems that even our present is more limited than we had realized; there are unimaginable abysses that we cannot reach and that cannot send any message to us. The science-fiction writers cheat when they put their spaceships in "overdrive" or use their "space-warp" to overcome the harsh reality that makes the nearest star four years of travel away, even if we are to travel at the maximum speed that (so far we know) any physical reality can, i.e., that of light.

Looking in the other direction, towards the very small, another sort of problem is emerging. The experimental probing of the nucleus takes vast quantities of concentrated energy. As we go downwards in scale, stability is greater, and it becomes more and more difficult to separate constituents. The macroscopic effects of atomic structure (color, melting point, etc.) can all (or nearly all) be explained without going further in the structuring of the atom than the nucleus. The evidence that allows us to go further than this and ask about electron or nucleon structure is itself of a highly sophisticated kind; it is produced by our machines, and only occasionally by such "natural" events as cosmic rays. As time goes on and machines get bigger and more complex, questions arise about the focusing of energy on tiny areas, and it is obvious that such focusing cannot be indefinitely improved. There is a limit to the amount of energy available, and to the means by which we can bring it to bear. It is not a sharp limit, of course, but it does remind us that the picture of physicists probing ever deeper into the worlds within worlds runs into problems at the very first step: getting the data.

A better-known limit is that furnished by the quantum uncertainty principle. This principle has many formulations, but they reduce to two. One relies upon an analysis of measurement and the interaction it neces- 
sarily causes. Because of the "granular" structure of this interaction (symbolized by Planck's constant, $h$ ), it can never be exactly calculated, and so every measurement, at any level, is accompanied by a disturbance to previously known parameters of the system, one whose amount cannot be exactly calculated. The other form of the principle is more fundamental, and is rooted in the quantum formalism governing the state-description of subatomic entities. Because the parameters are mathematically noncommuting, certain pairs of them cannot be sharply defined or predicated. If one is dealing with an ensemble, this causes no problem because perfectly definite statistical descriptions and predictions can be given. But if one is trying to handle an individual case, quite basic uncertainties arise. For instance, the quantum state-description of a radium atom could never, even in principle, tell us exactly when the atom would disintegrate. It could only give a probability distribution, at best.

At first sight, it might seem as though this was simply a weakness of the formalism; after all, it has always been true that a given theory could not handle all the "fine-structure" problems presented to it. When quantum theory is incorporated (as all theories ultimately are, it would seem) in a wider formalism, why should the new theory not be able to give a more exact acount of such things as the decay of individual radium atoms? In the forty years since Heisenberg, Bohr, and Dirac first proposed their uncertainty principle, this question has given rise to continuing controversy, and there is still no agreement as to how it should be answered. The "Copenhagen" group from the beginning took their discovery to have a sort of ontological significance. The "uncertainty" in the theory mirrored a real "indeterminism" in nature. It is quite striking to note that this interpretation, which ran so violently counter to the whole spirit of Newtonian science, caught on with physicists almost immediately, and in a short time 
became the self-styled "orthodox interpretation." This is all the more surprising in that no compelling evidence, especially none of a conventional scientific sort, could be given for it. It was either supported by extrascientific philosophic views (as in the case of Heisenberg and Destouches), or more often rested on a sort of "hunch". Von Neumann attempted to show in 1932 that all future theories of the subatomic will have to contain analogue of the uncertainty principle, if they are to account for the data accounted for in the present theory. But it seems agreed today that his proof contains serious petitio principii.

Opponents of the "orthodox interpretation" can be divided into two classes. There are those, first, who defend the opposite ontological thesis, determinism, and claim that further research must reveal the hidden parameters that govern action at all levels, including the subatomic. According to Einstein, Planck, de Broglie, a theory that incorporates an "uncertainty principle" is an imperfect theory by definition, one that confesses our present ignorance. In their view, the predictive uncertainty of quantum theory is no more than a defect of the present formalism, one that all analogies from the past assure us will sooner or later be overcome. Some more recent supporters of th: - view (Bohm and Vigier) would say, more cautiously, that underlying every "indeterminism" of theory is a "determinism" at a deeper level, and that the future progress of quantum theory will be a continuing dialectic between deterministic and indeterministic theories. Marxist physicists on the whole appear to lean to this interpretation rather than to the "orthodox" one still favored in the West.

But there is another possibility. One can question the Copenhagen interpretation without necessarily landing in the Bohm-Vigier camp. For on the balance of the present evidence, it would seem that neither side can enforce his view. Either interpretation is open as far as the scientific 
evidence goes. If one is to be preferred, it must be on philosophical or other grounds. Such grounds can, of course, constitute a perfectly valid warrant for interpreting the implications of a scientific theory, but it is not all clear that either side in this controversy is able to provide a philosophy of nature that is sufficiently elaborated to carry the weight being put upon it. The third view, which would hold that there is at the resent stage no conclusive evidence in favor either of indeterminism or of determinism, would seem to be preferable.

Without taking sides in the Bohr-Bohm controversy, then, it is still possible to note one very important consequence for our theme. Classical physics assumed complete predictability in principle; in practice, it was not always attainable, but it was always believed to be available, given enough time. This is no longer the case. We simply do not know whether the physics of the future will restore complete predictability, even at the level of such relatively large-scale events as atomic disintegrations. It may do so or it may not. We do not yet have the "Gödel theorem" of quantum theory that Von Neumann's proof for a long time was believed to be, i.e., a proof of the impossibility of finding a theory that would restore complete predictability. But leaving aside the fact that the majority of contemporary Western physicists appear to believe (without any really satisfactory proof) that such a theory never will be found, it is most important to recognize that they may be right i.e., the present quantum uncertainty may very well turn out to be a permanent barrier to complete predictability, a feature of all future theories. We cannot be sure, but there are indications that it is quite possible.

Once agan, if this be the case, it is not that present theory has exhausted the physical reality, but rather that it has said all that theory is able to say, even though there is much more that one would want it to say. 


\section{$\S 3$ The Conditions of Scientific Enquiry}

Science is a human activity. What touches man will thus touch science too. The future of science depends on the future of man: each alike could be wiped out in an instant of decision. Apart from this now never-absent possibility, might there be inherent limits to science arising from the fact that it is man's work? After all, the human mind is a finite thing; it is presumably not capable of indefinite development. For science to have an unlimited future, would the human mind itself not have to develop? Progress in science is not merely in extension, but in depth and difficulty also. The lifetime of science is counted in centuries, and most of it is crammed into the last few. At the present rate of growth-the familiar and probably inaccurate claim that $90 \%$ of all professional scientists who have ever lived are alive today, comes to mind-can we meaningfully speak of science in the year $3000 \mathrm{AD}$ ? or 30,000 $\mathrm{AD}$ ? 300,000AD? Man himself has been around longer than 300,000 years, but the imagination cannot even carry us to 3000 $\mathrm{AD}$. Is there any reason at all to suppose-as is so often supposed in recent years-that the growth of science can continue along the exploding curve of the last fifty years indefinitely, provided no universal human calamity intervene? If the answer is:none, what are the most likely limiting factors on the side of man? ${ }^{3)}$

What does scientific enquiry take? It takes memory, motivation, imagination, among other things. Each of them suggest future-indeed, present-headaches. The process of human learning is conditioned by biological and psychological factors. We are only beginning to appreciate

3) The quantum physicist Eugene Wigner was one of the first to draw attention to this question. See "The limits of science" in Readings in the Philosophy of Science, ed H. Feigl and M. Brodbeck, New York: Appleton-Century-Crofts, 1953, pp. 757765 . 
some of these, and spectacular progress, not only in learning theory, but also in its practical applications, seems right around the corner. But with all of this, the pace of learning is still finite, and so is the human life-span. The creative years of a scientist are short, but already the paths to the frontier are dangerously lengthening. It is possible to plan educational short-cuts, to drop whole areas and get quickly to areas of contemporary concern. But because scientific knowledge develops mainly by adding new "vertical" layers rather than by making "horizontal" forays here and there, this kind of condensation is possible only up to a point. One can omit classical theories of elasticity, for example, in teaching a student quantum electrodynamics, but one could not omit classical dynamics entirely, or else the student will not really understand. To understand complex theories like general realtivity theory, a great deal of prior work on vectors and tensors, on dynamical explanation, is indispensable. In a certain sense, the mind has to recapitulate the history of the theory, up to a point at least, in coming to understand it fully. This is especially true if he is not just to understand it, but to play a role in developing it further. The creative mind has to break the rules, make unexpected connections, but to do this a thorough grasp of the rules (and a feel for how they have been "broken" in the past) is required.

It is already the case in domains like physics that experts are completely out of sight of one another, each busy in his own excavation, the sounds of digging in other excavations quite muffled by distance. They will not know each other's theories, though they still can as a rule understand them if they make a great effort. But life is short and effort is precious, and the Physical Review keeps doubling in size. Each year hundreds of thousands of papers in physics are published; several thousands of them are likely to be directly relevant to any given area of concern. It is not enough 
to gesture optimistically to the computer. Information retrieval of physical facts is very helpful, but there is no way of mechanically "compiling" different theories. One has to read them and understand them, and that takes time and energy. And the good researcher needs to know all, or at least most, of the theories that could conceivably be relevant to his quest, as well as to have a good sense of their strengths and weaknesses.

It is a problem, then, of both depth and extent. To understand a theory often requires a long learning process; a worthwhile scientific theory can never be immediately grasped by the untrained mind. Science keeps proliferating in all directions; no one can keep track of all the important contributions, even to an area as well-defined as physical chemistry, for example. Yet for effective work in the area, one has to be able to establish interconnections of a conceptually furuitful sort. We stand aghast at the difficulty of reaching the frontiers today; very few educated people do (or could, without considerable further training) understand what is going on today in quantum field-theory, for example. But here we are, after only a few decades of really intensive exploitation of science, appalled already at the problems of understanding, or even finding out about, what is going on-and yet we speak glibly in terms of centuries ahead! There is, it might well seem, something facile about such an optimism.

That scientific enquiry depends critically upon the motivation of its practitioners hardly needs to be said. It is abstract, demanding, lonely work with little of the immediacy and warmth of other human activities. It makes enormous emotional demands; it sometimes calls for unusual sacrifices of the most "human" things in life, evenings with the family, leisure with a good book... Of course, it can be done as a"job,"and as scientific personnel in government and industry multiply, this will probably become more and more common. But the creative scientist, the one who is likely to push his 
science into new reaches, is separated from the life of his fellow citizens by years of decisions that others, as gifted as he, have been unable to make. Out of the millions who graduate from high school in the United States, for example, a mere couple of hundred reach a $\mathrm{Ph}$. $\mathrm{D}$. in mathematics each year. And as everyone knows, even a Ph.D. is no necessary proof of creativity.

When one thinks of the vast structure of industry and education in the United States, the crucial role played in both by mathematics, and the desperate shortage of creative mathematicians despite the financial inducements that government and graduate school have been offering, it leads one to conclude that creativity does not necessarily respond to social need. There undoubtedly thousands out of America's millions, who have the intellectual ability to become first-rate mathematicians. One of the reasons why more do not is surely the strong, almost overpowering, motivation the student must have in order to take upon himself this kind of isolated absolute effort, so unlike anything his more easygoing neighbor has to encounter. The demand for such effort comes especially in late adolescence and early manhood, and it is just at that period that the student of today finds himself increasingly under emotional pressure from a society which in so many ways challenges and dissipates intellectual effort.

Some of the motivation impelling students who take on the years of preparation necessary for advanced work in today's science surely comes from the strong feeling that science can make over the world and relieve its wants. As these wants come more and more to be fulfilled, and science goes off along less immediately serviceable ways (to the moon, for example), will the motivation hold up? The good physics student feels from the beginning of his work something of the excitement that has urged men onwards to know ever since the first astronomers left their warm beds for 
lonely hours of bleary-eyed measurement. But as physics becomes more abstruse and the moving frontier further off, will this continue to be so? It is not at all clear that it will and creativity in such a case may not answer the command of government to carry the curve of scientific research upward to new and more distant heights.

\section{$\S 4$ Analogy and Discovery}

Scientific progress is dependent most of all upon the imagination of individual scientists. In conclusion, then, it may be well to take a hard look at the conditions of scientific discovery, and to ask whether any of them suggests a built-in limitation. Discovery in physical science has not been just of one kind, one can disocver all sorts of things: facts, hypotheses, regularities, concepts; the notion of discovery itself is rather different in each case.4) To discover a regularity in a set of data, it might be enough to run the data through a computer, though there will of course be elements of personal decision in the choice of data and in the definition of curve criteria to be programed into the computer in advance. Even in the discovery of empirical regularities, then, rule-bound mathematical formalisms play the role of necessary condition, never sufficient condition. Non-mathematical unformalized skills and insight, oriented specifically to the physical order and trained by years of familiarity with that order, will be needed in the discovery of even the simplest physical law. $\left.{ }^{5}\right)$

This is even more true of discovery in the realm of hyptothesis and concept. Newton's great achievement was not just to discover novel numerical correlations, but to construct a network of complex physical

4) See E. McMullin, "Freedom, creativity, and scientific discovery", in Freedom and Man, ed. J. C. Murray, New York: Kenedy, 1965, pp. 105-130.

5) See Michael Polanyi's works, especially The Tacit Dimension, New York: Doubleday, 1966. 
concepts (mass, acceleration, force...). The syntax of this network was provided by the differential calculus, but its reference to the physical order, that which made it physics rather than mathematics, was of a far more complex kind. The concepts he used had already a physical meaning of sorts given by ordinary usage. Guided by these meanings, he provided an operational linkage between the conceptual system as a whole and the data of measurement. The analogies leading him from the traditional philosophical concept of matter to his own quasi-operational concept of mass were of a specifically physical sort. ${ }^{6}$ )

Since this is a cruical point, let us press it a little more closely. A purely formal system is a dead system; it has no resources for further development, since the symols are defined exclusively in terms of their internal relations with one another. There is no dynamism, nothing that will force a change. Only some sort of "surplus value" in the meanings of the terms can guide significant development. ${ }^{7)}$ Where the system is a mathematical one, the terms have a "surplus value" deriving originally from the experience of multiplicity, space, and the like, but now developed to a far more sophisticated level. The notion of group, for example, is not exhusted by some formal definition: the notion has shown itself capable of extension and generalization, following the characteristic lines of mathematical analogy, just as the concept of number did at an earlier stage. Even in the most formalist of logical systems, one will usually find a handhold for future extension in the broader categories of inference that the system is supposed

6) See E. McMullin, "From matter to mass", in Boston Studies in the Philosphy of Science, ed R. S. Cohen and M. W. Wartofsky, New York: Humanities Press, 1965, pp. 25-45, and The Concept of Matter in Modern Thought, Notre Dame: University Press, to appear Spring 1972.

7) See Mary Hesse, Models and Analogies in Science, Notre Dame: University Press, 1966, especially Chapter 2, "Material analogy". 
to explicate. Lacking such a handhold, discovery is reduced to internal manipulation (as in finding the shortest single axiom for a given system, for example).

In a physical theory, likewise, some terms must have a surplus value, a resonance that has not as yet been made fully explicit, or else the system is inert, unable to meet fresh challenge. It was from the surplus value of such concepts as space, time, force, that Einstein reconstructed mechanics in a new style. These concepts left room to move; not only that, but they themselves implicity suggested the direction the movement might take, so to speak. From the internal explicit formal structure of Newtonian mechanics alone, the new theory could not have been derived, not even with the aid of new results of measurement such as were given by the Michelson-Morley experiment. Not all scientific discoveries involve basic conceptual shifts, but the ones that do are the crucial ones for the scientific enterprise as a whole. And in them the physical reference is what ultimately provides the "surplus value."

This can be seen even more clearly in the case of models. The physicist uses models all the time in his theory-construction. They play a central role in discovery-just think of Bohr's model of the planetary atom, or the CrickWatson model of DNA. The "model" in each of these instances is a spatially differentiated structure, in which elements whose properties are postulated are related spatially and dynamically with one another. The model there precedes the theory. Indeed, it is from the model that the theory is derived, even though once derived, the theory takes scientific precedence. The model not a mere summary of the data, it goes far beyond them. ${ }^{8)}$ It is the "be-

8) See E. McMullin, "What do physical models tell us?", in Logic, Methodology and Philosophy of Science, Proceedings of Amsterdam Congress in Philosophy of Science, ed. J. F. van Rootselaar, 1968, Vol. 3, pp. 385-396. 
yond" that must be emphasized, as well as the intrinsic resources that the model seems to bring to the aid of discovery. When Sommerfeld was trying to explain some second-order effect in the hydrogen spectrum, he modified the original circular orbit proposed by Bohr and made it elliptical, thus accounting for the anomalous results. Had he merely taken Bohr's theory as a mathematical formalism, there would have been no reason to try this hypothesis. Instead, he saw the electron orbit as an approximation to physical reality, and this led him to regard the electron as an individual entity in a definite orbital path. Another example of a fruitful sort of model is by the notion of spin which has guided so many of the fundamental discoveries in quantum theory.

If our thesis is correct (i.e., that models and concepts with a root-sense in experience have played a central part in past scientific discovery), then it may well be that the most threatening barrier to the future of scientific enquiry lies right here. As our theories move further into the very large and the very small, their anchorage in our familiar middle-sized experience becomes less and less secure. We are forced to modify them in ways that seem paradoxical: we have to combine the metaphor of "wave" (periodic transmission) with that of "particle" (discrete interaction) in order to understand quantum theory, for example. The structural and dynamic metaphors whose roots of meaning (and thus whose "surplus value") lie in the world of perception gradually thin out as we descend into the world of the nucleus.

Indeed, it is not clear whether the notion of spatial structure can be properly applied to entities like electrons at all. The statistics is not the statistics of individual entities; except perhaps under special circumstances, they must not be regarded as individuals. Yet only individual localizable entities can have structure in the ordinary spatial sense 
of that term. It is obvious that we are becoming more and more remote from the levels where analogies drawn from the middle-sized world could guide discovery. The basic concepts of clasical physical understandingspace, time, motion-are still used in a cautious way in quantum electrodynamics, but pardoxes have developed, and their "surplus value" is no longer quite so trustworthy.

If one looks at recent fundamental particle theory, one is immediately struck by its almost purely mathematical character. Physics has always used mathematics but this is different. Newton used the differential calculus as a convenient syntax, but the weight of his system lay, as we have seen, in its crucial physical concepts, mass and force. Though a numerical measure of mass was possible, the concept itself could not be defined in mathematical terms: its "home", the locus of its "surplus value", was in the physical world. But nowadays physicists use group theory not just as syntax, but almost as carrying its own semantics as well. Calculus did not tell us how planets would move (until we had made some crucial physical assumptions about force), but group theory is almost expected to provide us with a theory of fundamental particles, unaided. It is clear that the "surplus value" at the frontiers of nuclear research today lies much more in mathematics than in physics.

It is also clear that discovery becomes progressively more difficult at this remote level. The traditional source of "surplus value" is drying up, and physicists have to fall back more and more on the reserves of mathematics. They have always had these reserves at their disposal. But they had more, much more, and it was from these nonmathematical reserves that most of the historic discoveries of science have proceeded. Our query is now clear: Can we be assured that the resources of mathematics alone will be sufficient to carry physical enquiry, as properly physical concepts and 
models become ineffective? To answer this in the affirmative might seem to commit one to a mathematical ontology of a Pythagorean kind (as Heisenberg has already noted). But even if it does not, the question of discovery must be faced: as sceience penetrates into the nucleus, where will the "surplus value" that we have seen to be so central to past discovery in science come from? Will the human mind, which after all is inescapably bound to the physical order in which it first learns to understand, continue to move freely in the distant realm of the sub-atomic, freely enough at least to wander onwards as it has in the past?

\section{§5 Conclusion}

Our purpose here has been to raise questions, not to make assertions about what will, or will not, happen to scientific enquiry. It is the custom of science to predict, and the power of one's prediction depends upon the solidity of one's theory. It is surely not unscientific to hazard some predictions about the future of science itself, though the basis for these predictions be far from assured. That they should be partially negative and not straightforwardly optimistic as they might have been fifty years ago, reflects not a desire to limit the ambitions of science, but rather an honest attempt to see where it may, and where it may not, go.

Classical science was rationalistic in its implicit claim, for it supposed that the physical reality could in principle be completely grasped by the human mind; a particular physical theory could express the final word on an entire domain. Thus physical reality was viewed as exhaustible, after the fashion of a mathematical system (pre-Gödel). In this view, science could come to a stop, but not because it had said everything there was to say. Its horizons were limited ones, therefore, in the sense at least that scientific enquiry in one area after another would be expected to come to a halt. In another sense, of course, the horizons of science itself would be limitless, 
since scientific insight appeared able to penetrate the secrets of Nature until all was comprehended. The "limits" were not barriers, then, impediments to further progress where interesting and meaningful questions may be left without answer. In this essay, we have seen reason to suppose that such barriers may exist. If they do, they would lie in the constitution of the world and of man as knower. Against the expectation of clasical Newtonian science, we are arguing that the world is not exhaustible, that no theory is ever definitive. While against the expectation of early twentiethcentury science, we propose that this inexhaustibility ought not too easily be taken to imply an endless source of continuous future progress for science. There just might be things worth knowing that man will never know.

\section{筆者紹介 :}

Ernan Mcmullin, 1924年アイルランドのドンガルイ生れる。始め理論物理学者として研 究生活に入り, ダブリン高等研究所, ルーヴァン大学等において研究, 次第に哲学に関心 を深め, 1954年, ルーヴァン大学より哲学の Ph. D. を受ける。1954年渡米, 米国ノートルダ ム大学哲学科講師に就任, 現在同哲学科主任教授。その間にイエール大学, ミネンタ大学 客員教授, ケンブリッジ大学客員研究員。1970年以来 Philosophy of Science Association 理事, 編著に Concept of Matter, Galileo Galilei 等がある。 